\title{
Palmar Cutaneous Branch of Median Nerve: An Anatomical Study
}

\author{
Rama Cutánea Palmar del Nervio Mediano: Un Estudio Anatómico
}

Edie Benedito Caetano ${ }^{1}$; Luiz Angelo Vieira ${ }^{1}$; Rodrigo Guerra Sabongi²; Caio Augusto

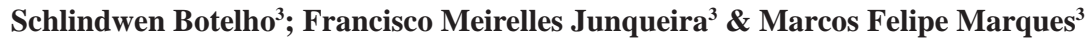

CAETANO, E. B.; VIEIRA, L. A.; SABOngI, R. G.; BOTELHO, C. A. S.; JUNQUEIRA, F. M. \& MARQUES, M. F. Palmar cutaneous branch of median nerve: An anatomical study. Int. J. Morphol., 36(2):531-536, 2018.

SUMMARY: The purpose of this study was to determine the origin, frequency and anatomical variations of the palmar cutaneous branch of the median nerve (PCBMN) and its clinical implications in surgical procedures such as decompression of the carpal tunnel and volar approach to the wrist. Dissection of 30 forearms from 18 adult male specimens ( 9 bilateral, 7 right limbs and 5 left limbs) were performed using 2.5X magnification loupe in order to better understand the PCBMN. Origin, number, length, positioning, anatomical relations and variations were recorded and analyzed. The PCBMN was identified in all dissected forearms, being the most distal branch of the median nerve in all forearms. The average origin was $4.8 \mathrm{~cm}$ (ranging 3.8 to $6.5 \mathrm{~cm}$ ) proximal to the wrist flexion crease. Anatomical variations of the PCBMN are not rare and could endanger the nerve during surgical approach for the volar wrist and proximal palm. We did not find the PCBMN positioned ulnar to the fourth metacarpal axis as well as radial to the flexor carpi radialis tendon.

KEY WORDS: Hand/Innervation; Median nerve; Cadaver; Anatomy.

\section{INTRODUCTION}

The palmar cutaneous branch of the median nerve (PCBMN) origins from the medial margin of the median nerve (MN) 3 to $8 \mathrm{~cm}$ proximal to the wrist palmar crease. It remains connected to the $\mathrm{MN}$ for a few millimeters and thenceforward separates as a cutaneous branch, emerging underneath or distal to the flexor digitorum superficialis (FDS) muscle. It follows a path parallel to the medial margin of the flexor carpi radialis (FCR) tendon, positioned between the FCR and the pamaris longus (PL) (Naff et al., 1993). Situated deep to the forearm fascia from its origin, the branch perforates this structure and is situated among the superficial and deep layers of the transverse carpal ligament (flexor retinaculum). Thereby, minuscule branches provide sensitive innervation to the thenar eminence and proximal palmar region (Das \& Brown, 1976; Bezerra et al., 1986; Hobbs et al., 1990; Naff et al.). The precise autonomic site of the PCBMN is difficult to define due to overlapping sensitive innervation in this area (Das \& Brown). The anatomy, origin, frequency and variations of this branch has been described by several authors (MacDonald et al., 1978; Hobbs et al.; Naff et al.; Lindley \& Kleinert, 2003). It is the last branch of the MN in the forearm and is usually present in all forearms (MacDonald et al.; Bezerra et al.; Hobbs et al.). Most authors correlates the anatomical positioning of the PCBMN with carpal tunnel release surgery (Taleisnik, 1973; MacDonald et al.; Matloub et al., 1998; Lindley \& Kleinert). However, few reports in the literature discusses its variations and practical risks during Henry's volar approach for distal radius fractures, scaphoid pseudoarthrosis through MattiRusse technique and surgical procedures involving FCR and PL tendon grafts (Dowdy et al., 1994; Nagle \& Santiago, 2008; McCann et al., 2012; Jones et al., 2016). The PCBMN is crucially endangered by variations during volar surgical approaches to the wrist and proximal palm (Das \& Brown; Bezerra $e t$ al.; Hobbs et al.). The aim of this study was to determine the frequency, origin and variations of the PCBMN and its clinical implications during surgery while evaluating its anatomical relations to the FDS, FCR and the fourth metacarpal axial line.

\footnotetext{
${ }^{1}$ Department of Surgery, Faculdade de Ciências Médicas e da Saúde, Pontifícia Universidade Católica de São Paulo (PUC-SP) - Sorocaba (SP), Brasil. ${ }^{2}$ Escola Paulista de Medicina, Universidade Federal de São Paulo (UNIFESP) - São Paulo (SP), Brasil.

${ }^{3}$ Residence in Orthopedics, Faculdade de Ciências Médicas e da Saúde, Pontifícia Universidade Católica de São Paulo (PUC-SP) - Sorocaba (SP), Brasil.
} 


\section{MATERIAL AND METHOD}

Thirty forearms from 18 adult male specimens $(9$ bilateral, 7 right and 5 left) were dissected in the anatomy laboratory of our institution. Forearms with scars and apparently affected by trauma or malformations were excluded. Dissection with a 2.5x magnification loupe (Keeler Instruments Inc., Malvern, PA) was carried through a midline incision in the volar surface of the forearm. A medial and lateral skin and subcutaneous flaps were created in order to expose the forearm fascia which was incised similarly. All underlying muscles were exposed and thoroughly dissected with attention to innervation, variations and $\mathrm{MN}$ compression sites. The PCBMN was identified in its origin near the distal margin of the FDS muscle (myotendinous junction) and followed distally. Examination proceeded in the interval between the FCR and PL tendons. Near the wrist, its fascial perforation was inspected until the innervation site. All anatomical variations were registered and photographed. The study was approved by the institution research ethical committee (FCMS/PUC-SP - 1.025.516).

\section{RESULTS}

The PCBMN was present in all dissected forearms, being the last branch of the MN (Fig. 1). In 18 forearms, its origin was proximal to the FDS muscle while 12 presented distally (Figs. 1 and 2). The mean origin site was $4.8 \mathrm{~cm}$ (ranging 3.8-6.5 $\mathrm{cm}$ ) proximal to the wrist flexion crease (WFC). In one right upper limb we have identified two PCBMN. The most proximal branch originated from the radial margin of the MN $17.5 \mathrm{~cm}$ proximal to the WFC and coursed distally parallel to the MN between the FDS and

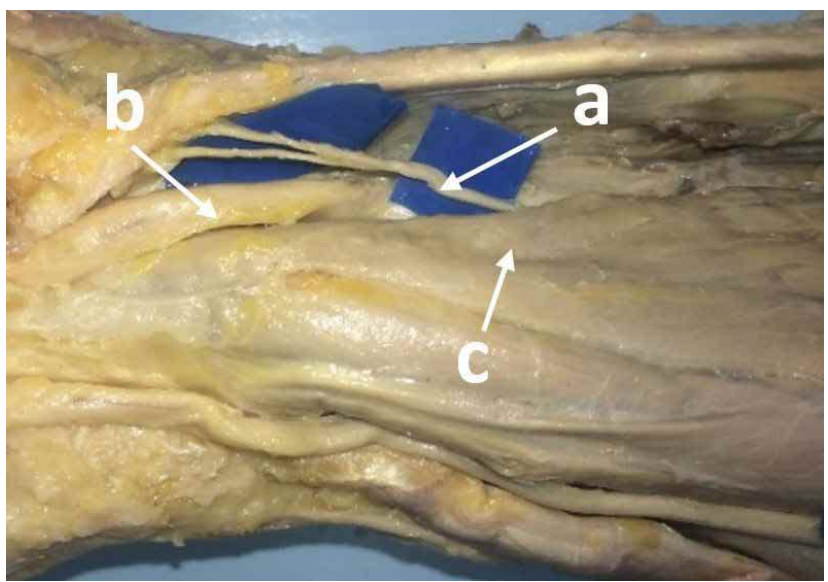

Fig. 1. In 18 forearms, the PCBMN (a) origin from the MN (b) proximal to the FDS muscle belly (c). flexor digitorum profundus (FDP) (Fig. 3A). The distal branch arose from the radial margin of the MN $5.2 \mathrm{~cm}$ proximal to the WFC $(0.5 \mathrm{~cm}$ proximal to the FDS myotendinous junction). This two branches were $12.3 \mathrm{~cm}$ apart and had parallel trajectories radial to the FCR tendon (Fig. 3B). Both branches perforated the forearm fascia and penetrated the carpal transverse ligament. Dissection was possible until $2 \mathrm{~cm}$ distal to the WFC. In the left upper limb

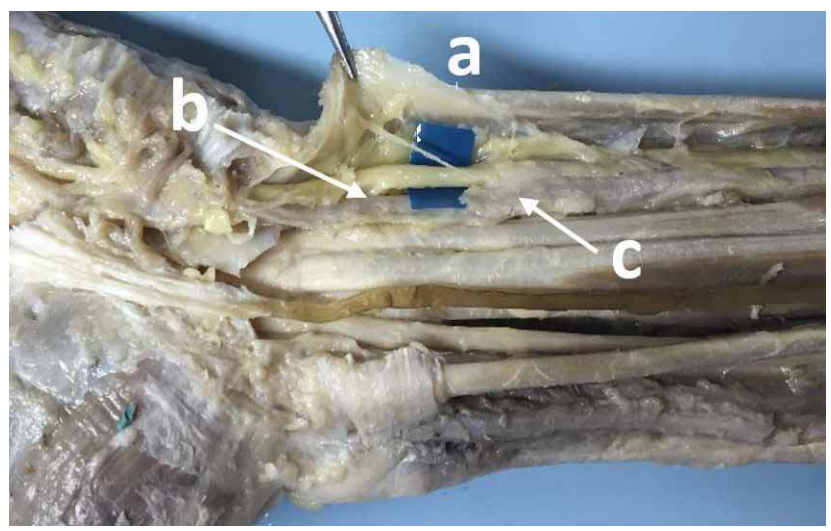

Fig. 2. In 12 forearms, the PCBMN (a) has its origin from the MN (b) distal to the FDS muscle belly (c).
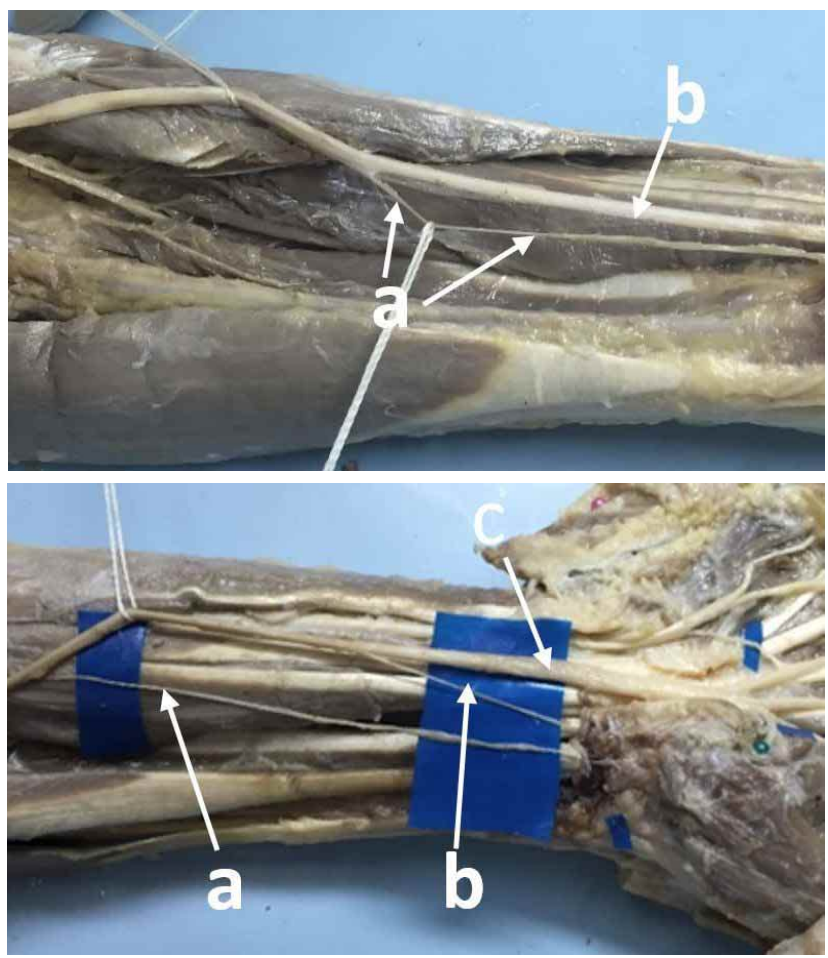

Fig. 3. A. In a right forearm from one specimen, two PCBMN were identified. The most proximal (a) originated in the radial margin of the MN (b) $17.5 \mathrm{~cm}$ proximal to the WFC. B. Both PCBMN (a and b) were parallel to the $\mathrm{MN}(\mathrm{c})$ and perforated the forearm fascia coursing between the transverse carpal ligament and the hand palmar fascia. 
of this specimen, we have identified an identical branch 15.5 $\mathrm{cm}$ proximal to the WFC which penetrated the FDS muscle

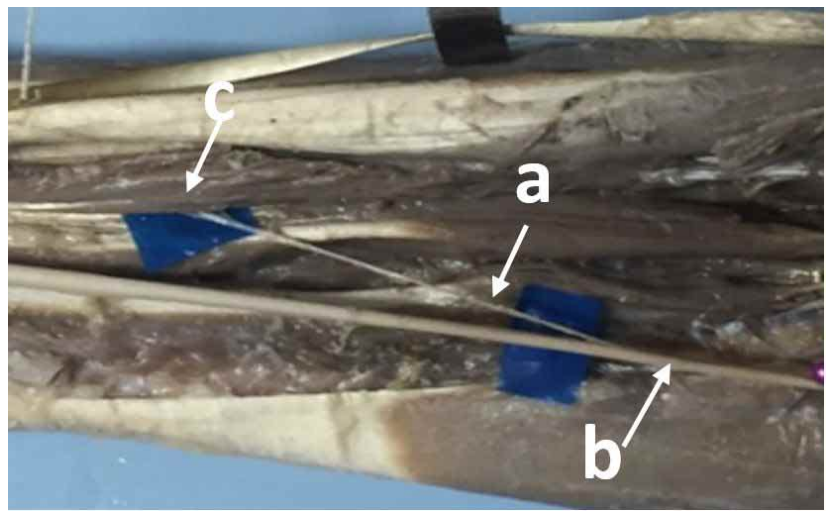

Fig. 4. In a left forearm from the same specimen, an identical branch was identified (a) with its origin from the MN (b) $15.5 \mathrm{~cm}$ proximal to the WFC. It perforated the FDS muscle (c) $7 \mathrm{~cm}$ distal to its origin.

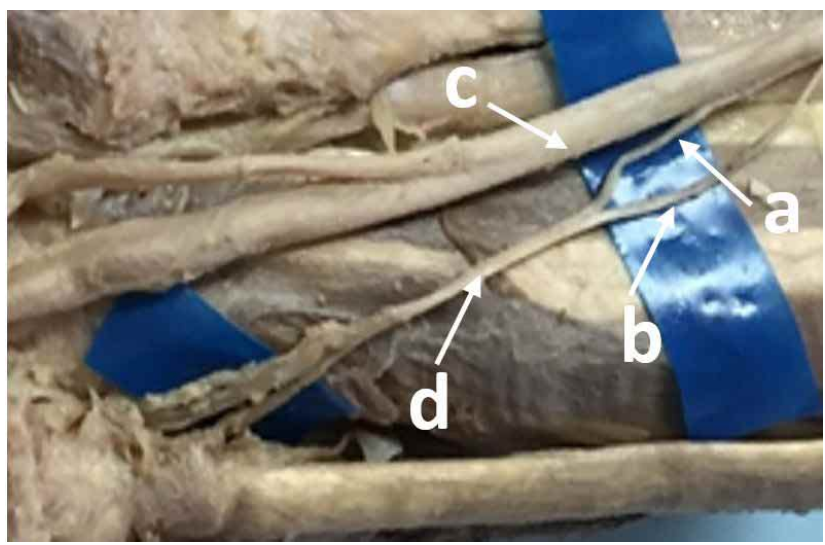

Fig. 5. In a right forearm from one specimen, two PCBMN (a and b) originated closely from the radial margin of the $\mathrm{MN}$ (c) and united after $2 \mathrm{~cm}$, following as one single branch (d) with ramifications proximal to the WFC.

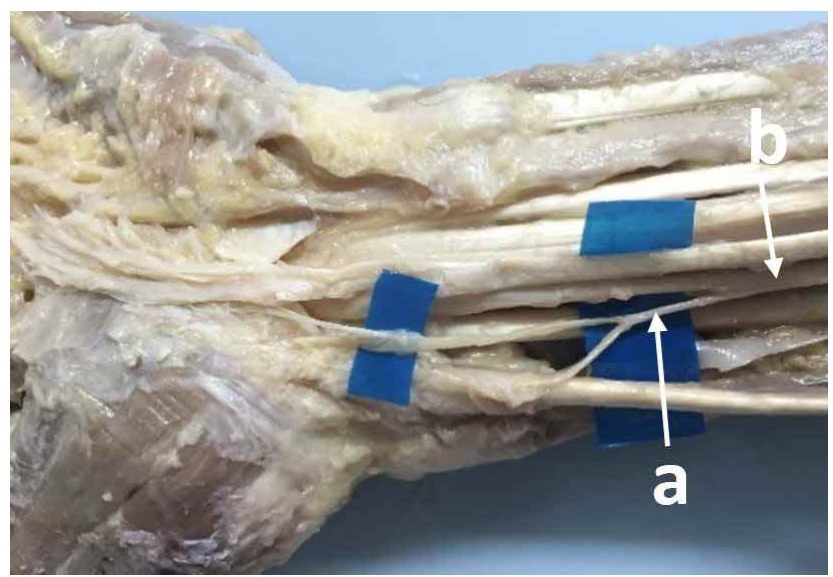

Fig. 6. A single PCBMN (a) originating from the MN (b) dividing in two branches. One positioned between the FCR and PL while the other penetrated the radial border of the FCR tendon sheath.
$7 \mathrm{~cm}$ from its origin (Fig. 4). In another specimen, the right forearm presented two very close branches that originated in the radial margin of the $\mathrm{MN}$ and united after $2 \mathrm{~cm}$, following as one PCBMN (Fig. 5). Other variation was identified in a left forearm in which a single PCBMN arose $4.8 \mathrm{~cm}$ proximal to the WFC and $1.5 \mathrm{~cm}$ from this landmark divided in two nerves: one positioned in the FCR and PL interval and the other penetrated the radial border of the FCR tendon sheath (Fig. 6). In 9 limbs, the PCBMN ramifications were proximal to the WFC (Fig. 5), while 21 they branched distally (Fig. 7).

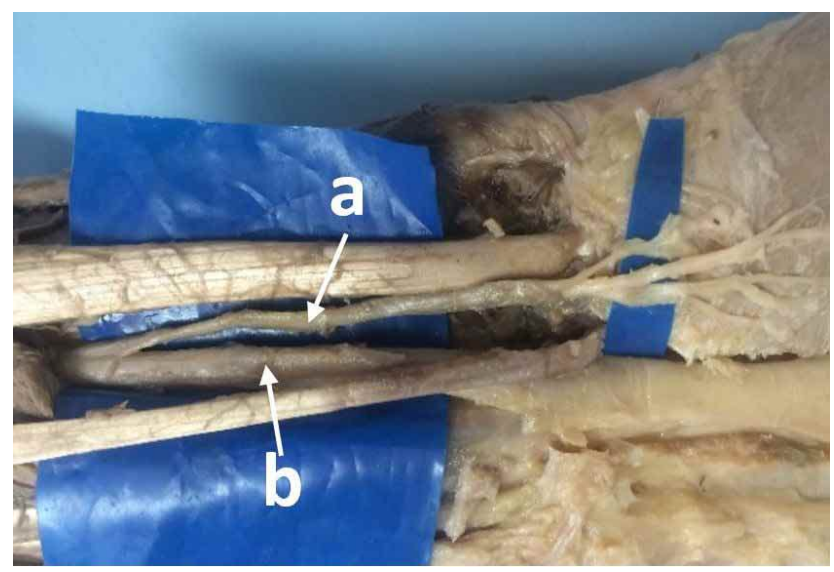

Fig. 7. In 21 forearms, the distal ramifications of the PCBMN (a) was distal to the WFC. Median nerve (b).

\section{DISCUSSION}

Anatomical variations of the PCBMN have been described in the literature with concern of the risk of injury, during procedures such as carpal tunnel release (MacDonald et al.; Lindley \& Kleinert), volar approach to the wrist for distal radial fracture fixation, scaphoid pseudoarthrosis treatment (Martin et al., 1996; Nagle \& Santiago), harvesting PL tendon graft, transferring FCR tendon and synovial cysts resection (Carroll \& Green, 1972; McCann et al.).

In our series, all PCBMN originated from the radial margin of the $\mathrm{MN}$, which is similar with most previous findings (Das \& Brown; Bezerra et al.; Hobbs et al.; Naff et $a l$.). However, some studies found cases of branching in the ulnar border (Das \& Brown; Matloub et al.). Also, there are reports of nerve communication with the superficial branch of the radial nerve (SBRN) near the first metacarpal base (Bezerra et al.; Hobbs et al.). Hobbs et al. dissected 25 fresh specimens and evaluated the PCBMN origin, course, terminal branches and anatomical variations and reported two cases of communication with the SBRN. In our series, there 
were no such relation, but due to the anatomical proximity, this communication is feasible.

The average origin of the PCBMN was $4.8 \mathrm{~cm}$ proximal to the WFC. Although Bezerra et al. reported similar results, with the branch arising $4.56 \mathrm{~cm}$ from the WFC, Hobbs $e t$ al. found a mean of $8.4 \mathrm{~cm}$. That was justified by the use of fresh specimens and the dissection of its real origin, sometimes hindered by formaldehyde preservation. A drawback in our study was the use of formaldehyde and glycerin preservation which may have made dissection of fascicles further than $2 \mathrm{~cm}$ from the WFC difficult. In contrast, fresh specimens can enable distal dissections up to $4 \mathrm{~cm}$ distal from this landmark (Hobbs et al.). Naff et al. described an average $5.7 \mathrm{~cm}$ in 21 limbs of 12 fresh specimens, with one originating $11 \mathrm{~cm}$ proximal to the WFC. We have not included in mean calculation an atypical case with two PCBMN, of which one arose $17.5 \mathrm{~cm}$ proximal to the anatomical landmark. Hobbs et al. also reported four cases with two PCBMN with a mean distance of $4.1 \mathrm{~cm}$ between each other. In one forearm, this gap reached $21.5 \mathrm{~cm}$ and in all they communicated distally. The case we presented the PCBMN were $12.3 \mathrm{~cm}$ apart. These authors did not identify nerve fibers extending ulnar to the ring finger axial line and postulated that incisions should be planned based in this anatomical knowledge (Hobbs et al.). However, the cases with direct communication with the SBRN the anastomotic branch would be injured even with adequate surgical planning. This could explain sensory alterations in the dorsal thumb after procedures in the volar surface of the wrist.

All anatomic studies in the literature did not described the absence of the PCBMN. Roche \& Ng (2014) reported a 67-year-old patient submitted to an MN re-exploration due to carpal tunnel syndrome. They performed external neurolysis and hypothenar graft over the MN and did not identify the PCBMN up to $8 \mathrm{~cm}$ proximal to the WFC. They postulated that a iatrogenic lesion from the first procedure performed 20 month earlier, under local anesthesia may have occurred, although vestige of the nerve was present. Lindley $\&$ Kleinert reported 31 anatomical variations of the $\mathrm{MN}$ in 526 carpal tunnel releases, of which 2 were related to the PCBMN. In one case, the branch perforated the flexor retinaculum and united again with the MN. In other, the branch was situated ulnar to the ring finger axial line.

MacDonald et al. reported 34 (12\%) complications after 186 open carpal tunnel releases. One third of which were injuries to the PCBMN, resulting in neuroma formation. Symptoms related to PCBMN injury range from light irritation to severe hand deficiency (Carroll \& Green). This branch is particularly prone to injury during Henry approach for distal radius fracture fixation due to its anatomical positioning, FCR tendon retraction and aggressive soft tissue manipulation (McCann et al.). Chronic wrist pain (pillar pain) has also been related to PCBMN lesion (Carroll \& Green; Taleisnik; Das \& Brown). Taleisnik highlighted the possibility of direct injury to this branch during volar approach to the wrist and to terminal fibers during skin incision in carpal tunnel release. Thereby, suggests an incision ulnar to the ring finger axial line curving to the ulnarly when crossing the WFC (Taleisnik). In an evaluation of 120 carpal tunnel releases, Das \& Brown reported 17 unsatisfied patients of which four were due to PCBMN lesion. Da Silva et al. (1996) performed an anatomical, histological and immunohistochemical study of the PCBMN and its ramifications in 12 fresh specimens. Small nonmyelinated fibers were identified in the soft conjunctive tissue of the superficial carpal transverse ligament. No nerve fibers were detected in the dense conjunctive tissue of the deep layer. Based on their findings, post operatory soft tissue pain may be justified by sectioning of the small terminal fibers after carpal tunnel release. However, during endoscopic release the superficial fibers of the ligament are spared and only the deep layers without nerve fibers are divided. Based on 40 limb dissections of fresh specimens, Matloub et al. concluded that some grade of nerve injury is present in the standard incision for carpal tunnel release. Therefore, they recommend a short incision in the proximal palm or a twin incision approach. Also, the authors advise that the FCR sheath should be opened on the radial side during transfer procedures.

Nagle \& Santiago reported a case of a 17-year-old girl undergoing surgical treatment for scaphoid nonunion. During surgical exposure, an anomalous PCBMN was identified crossing the FCR tendon superficially, $2 \mathrm{~cm}$ proximal to the WFC and lied in its radial aspect. No proximal dissection of the MN was performed to identify other branches in the usual anatomic position. Some authors recommend the incision in the radial border of the FCR during distal radius fracture approach, in order to avoid injury to this PCBMN (Carroll \& Green; Hobbs et al.; Matloub et al.). During exposure of the distal radius and scaphoid, the knowledge of anatomic variations and meticulous dissection of the FCR are fundamental to avoid nerve injury (Nagle \& Santiago). Articular capsule innervation by the PCBMN is questionable, as well as the need to severe its fibers during wrist denervation procedures (Matloub et al.). Function of these fibers and its possible contribution to acute and chronic wrist pain remains uncertain.

In an anatomic study of the cutaneous branches of the median and ulnar nerves, Martin et al. reported the presence of the PCBMN in all 25 dissected hands, of which 3 could be endangered by a carpal tunnel release incision. 
Incision based on the axis of the ring finger would likely compromise branches of the palmar cutaneous branch of the ulnar nerve in 16 specimens. The authors postulate that decreased pain in patients undergoing endoscopic release could be related to preservation of these branches (Martin et al.). Xu et al. (2013) described a safety zone for carpal tunnel release based on the cross point of the middle finger axis and WFC. Incisions carried $5 \mathrm{~mm}$ ulnar and $6 \mathrm{~mm}$ radial to this point could be considered relatively safe. In a study of 182 distal radius fracture volar plating fixation involving 10 hand surgeons, there was $8 \%$ PCBMN crossing or perforating the FCR tendon sheath. Although no nerve injuries were reported, the safety of the Henry approach should be reassessed and care should be taken during FCR tendon sheath incision. Dowdy et al. performed an anatomical study of $52 \mathrm{limbs}$ with the objective of determine the relationship between the PCBMN and PL tendon. In 2 cases, the nerve passed through the PL fibers $1 \mathrm{~cm}$ and $1.5 \mathrm{~cm}$ proximal to its insertion into the palmar aponeurosis. This variation could compromise the nerve during tendon graft harvesting. In order to avoid injuries, the authors recommend preserving a margin of $2 \mathrm{~cm}$ proximal to its insertion of tendon during transection of the PL (Dowdy et al.). Bertelli (2012) reported the use of the PCBMN for sensitive nerve transfer to the ulnar proper digital nerve of the little finger in lower-type injuries of the brachial plexus.

In contrast to $\mathrm{MN}$ compressive syndromes, isolated compression of the PCBMN is uncommon with few reports in the literature related to atypical PL muscle (Stellbrink, 1972), FCR tendon sheath cysts (Gessini et al., 1983; Buckmiller \& Rickard, 1987) and FDS muscular fascia (Shimizu et al., 1988). In 18 specimens, we have identified the PCBMN origin deep to the FDS muscle, however no compressive fibrous bands were present. The possibility of compressive syndromes from hypertrophied muscle in athletes is feasible. Tendinitis of the FCR could induce palmar pain due to proximity to the PCBMN (Naff et al.). Patients may complain of symptoms related to nerve compression following hand and forearm injuries with soft tissue edema. We did not register any anatomical structure that could cause isolated compression of the PCBMN in our dissections.

\section{CONCLUSION}

Anatomical variations of the PCBMN are not rare and could endanger the nerve during surgical approach for the volar wrist and proximal palm. We did not find the PCBMN positioned ulnar to the fourth metacarpal axis as well as radial to the FCR tendon.
CAETANO, E. B.; VIEIRA, L. A.; SABONGI, R. G.; BOTELHO, C. A. S.; JUNQUEIRA, F. M. \& MARQUES, M. F. Rama cutánea palmar del nervio mediano: Un estudio anatómico. Int. J. Morphol., 36(2):531536, 2018.

RESUMEN: El objetivo de este estudio fue determinar el origen, la frecuencia y las variaciones anatómicas de la rama cutánea palmar del nervio mediano (RCPNM) y sus implicaciones clínicas en procedimientos quirúrgicos como la descompresión del túnel carpiano y el abordaje palmar de la muñeca. Se realizó la disección de 30 antebrazos de 18 especímenes adultos de sexo masculino ( 9 bilaterales, 7 miembros derechos y 5 miembros izquierdos) utilizando una lupa de aumento de 2,5X para comprender mejor la RCPNM. Origen, número, longitud, posicionamiento, relaciones anatómicas y variaciones fueron registradas y analizadas. El RCPNM fue identificado en todos los antebrazos disecados, siendo la rama más distal del nervio mediano en todos los antebrazos. El origen promedio fue de $4,8 \mathrm{~cm}$ (rango de 3,8 a 6,5 cm) proximal al pliegue de flexión de la muñeca. Las variaciones anatómicas de la RCPNM no son raras y podrían poner en peligro el nervio durante el abordaje quirúrgico de la cara volar y palmar proximal de la muñeca. No encontramos el RCPNM posicionado a nivel ulnar del cuarto metacarpiano, así como radial al tendón del músculo flexor radial del carpo.

PALABRAS CLAVE: Mano/Inervación; Nervo mediano; Cadáver; Anatomía.

\section{REFERENCES}

Bertelli, J. A. Distal sensory nerve transfers in lower-type injuries of the brachial plexus. J. Hand Surg. Am., 37(6):1194-9, 2012.

Bezerra, A. J.; Carvalho, V. C. \& Nucci, A. An anatomical study of the palmar cutaneous branch of the median nerve. Surg. Radiol. Anat., 8(3):183-8, 1986.

Buckmiller, J. F. \& Rickard, T. A. Isolated compression neuropathy of the palmar cutaneous branch of the median nerve. J. Hand Surg. Am., 12(1):97-9, 1987.

Carroll, R. E. \& Green, D. P. The significance of the palmar cutaneous nerve at the wrist. Clin. Orthop. Relat. Res., 83:24-8, 1972.

Da Silva, M. F.; Moore, D. C.; Weiss, A. P.; Akelman, E. \& Sikirica, M. Anatomy of the palmar cutaneous branch of the median nerve: clinical significance. J. Hand Surg. Am., 21(4):639-43, 1996.

Das, S. K. \& Brown, H. G. In search of complications in carpal tunnel decompression. Hand, 8(3):243-9, 1976.

Dowdy, P. A.; Richards, R. S. \& McFarlane, R. M. The palmar cutaneous branch of the median nerve and the palmaris longus tendon: a cadaveric study. J. Hand Surg. Am., 19(2):199-202, 1994.

Gessini, L.; Jandolo, B.; Pietrangeli, A. \& Senese, A. Compression of the palmar cutaneous nerve by ganglions of the wrist. J. Neurosurg. Sci., 27(4):241-3, 1983.

Hobbs, R. A.; Magnussen, P. A. \& Tonkin, M. A. Palmar cutaneous branch of the median nerve. J. Hand Surg. Am., 15(1):38-43, 1990.

Jones, C.; Beredjiklian, P.; Matzon, J. L.; Kim, N. \& Lutsky, K. Incidence of an anomalous course of the palmar cutaneous branch of the median nerve during volar plate fixation of distal radius fractures. J. Hand Surg. Am., 41(8):841-4, 2016.

Lindley, S. G. \& Kleinert, J. M. Prevalence of anatomic variations encountered in elective carpal tunnel release. J. Hand Surg. Am., 28(5):849-55, 2003.

MacDonald, R. I.; Lichtman, D. M.; Hanlon, J. J. \& Wilson, J. N. Complications of surgical release for carpal tunnel syndrome. J. Hand Surg. Am., 3(1):70-6, 1978.

Martin, C. H.; Seiler, J. G. 3rd \& Lesesne, J. S. The cutaneous innervation 
of the palm: an anatomic study of the ulnar and median nerves. J. Hand Surg. Am., 21(4):634-8, 1996

Matloub, H. S.; Yan, J. G.; Mink Van Der Molen, A. B.; Zhang, L. L. \& Sanger, J. R. The detailed anatomy of the palmar cutaneous nerves and its clinical implications. J. Hand Surg. Br., 23(3):373-9, 1998.

McCann, P. A.; Clarke, D.; Amirfeyz, R. \& Bhatia, R. The cadaveric anatomy of the distal radius: implications for the use of volar plates. Ann. R. Coll. Surg. Engl., 94(2):116-20, 2012.

Naff, N.; Dellon, A. L. \& Mackinnon, S. E. The anatomical course of the palmar cutaneous branch of the median nerve, including a description of its own unique tunnel. J. Hand Surg. Br., 18(3):316-7, 1993.

Nagle, D. J. \& Santiago, K. J. Anomalous palmar cutaneous branch of the median nerve in the distal forearm: case report. J. Hand Surg. Am., 33(8): 1329-30, 2008

Roche, S. J. \& Ng, C. Y. Absent palmar cutaneous branch of median nerve. J. Hand Microsurg., 6(1):47-8, 2014.

Shimizu, K.; Iwasaki, R.; Hoshikawa, H. \& Yamamuro, T. Entrapment neuropathy of the palmar cutaneous branch of the median nerve by the fascia of flexor digitorum superficialis. J. Hand Surg. Am., 13(4):5813, 1988.

Stellbrink, G. Compression of the palmar branch of the median nerve by the atypical palmaris longus muscle. Handchirurgie, 4(4):155-7, 1972.

Taleisnik, J. The palmar cutaneous branch of the median nerve and the approach to the carpal tunnel. An anatomical study. J. Bone Joint Surg. Am., 55(6):1212-7, 1973.

Xu, X.; Lao, J. \& Zhao, X. How to prevent injury to the palmar cutaneous branch of median nerve and ulnar nerve in a palmar incision in carpal tunnel release, a cadaveric study. Acta Neurochir. (Wien), 155(9):17515,2013
Corresponding author:

Prof. Dr. Edie Benedito Caetano

Pontifícia Universidade Católica de São Paulo Faculdade de Ciências Médicas e da Saúde

Rua Joubert Wey, 290

CEP: 18030-070

Sorocaba, São Paulo

BRASIL

Email: ediecaetano@uol.com.br

Received: 01-12-2017

Accepted: 10-01-2018 